\title{
BREEDING SUGAR BEETS FOR INCREASE OF SUGAR CONTENT AND YIELD.
}

By J. E. W. Tracy, U. S. Department of Agriculture, Wașington, D. C.

\section{IMPORTANCE OF USING HIGH-GRADE SEED.}

The great importance of the quality of the sugar beet seed used, both to farmers and factories, can hardly be overestimated since both the percentage of sugar in the root and the yield of roots per acre are largely dependent upon it. In Germany, where the raising of sugar beet seed and the manufacture of sugar have probably reached their highest development, its importance is so thoroughly recognized that the most careful manufacturers insist upon having all the seed used by them grown under their own supervision and on such soils and under such climatic conditions as experience has shown to be best adapted to their particular localities. Here in America comparatively little attention is paid to this matter and consequently certain factories have been financial failures, largely, we believe, on account of negligence as to the actual character of the seed used. The reported extraction for all beets worked in the United States during $1905^{1}$ was 11.74 per cent or 234.8 pounds of commercial sugar manufactured from each ton of roots worked. The extraction secured in Germany in recent years has been somewhat over 15 per cent, or between 3 and 4 per cent more than in America. It is not conservative to say that the average percentage of extraction in this country could be increased at least half of this difference, or say 2 per cent, by the use of as highgrade seed as is used by the Germans. Such an increase of 2 per cent of available sugar in the root would make a difference of 40 pounds of refined sugar to each ton of roots worked, which to a factory working 50,000 tons of beets per year would mean an increase of $2,000,000$ pounds of marketable sugar. At this rate the total product of all the factories of the United States in 1905 would have been increased by more than 50,000 tons of refined sugar. Such an increase would mean the difference between profit and loss to many factories without any increase in the capital invested in their plants and with but a slight increase in the actual cost of production. Where a "flat rate," that is a uniform rate for all roots regardless of sugar content, is in vogue, there would be no additional expense for the roots; but where a " sliding scale" is used, the price paid depending upon the sugar content, an increase of 50 cents per ton for the roots would be incurred which, however, would go directly into the farmers' pockets at no additional cost to themselves. The cost of handling and slicing the roots and extracting the sugar would not be materially increased, the additional expense being in purifying and handling the finished product, both of which are comparatively inexpensive items in sugar manufacture.

${ }^{1}$ Figures for 1905 have been used throughout this article, since those for 1906 have not as yet been completed. 
The difference in the cost of the best and the cheapest grades of seed is rarely more than 4 cents per pound, so that allowing 18 pounds per acre for planting, the additional seed expense would amount to but 72 cents per acre. The average yield of roots for the entire United States last year was 8.67 tons per acre, which with an increase of 2 per cent in available sugar would give an increase of 346.8 pounds of sugar per acre, worth say $\$ 16$, at an additional cost of but 72 cents per acre for the seed. The total extra expense of seed for planting 10,000 acres, the area required for a 1,000-ton factory, would be $\$ 7,200$, while the sugar output would be increased by $3,468,000$ pounds, which, valued at $4 \frac{1}{2}$ cents per pound, would be worth $\$ 156,060$.

It is thoroughly believed in Europe, and our experiments here have shown, that the yield of beets is also largely dependent upon the quality of the seed used. There is no doubt that the small yield of 8.67 tons per acre secured in the United States in 1905 could be greatly increased if only high-grade seed were used. Germany's average yield for recent years has been over 13 tons per acre, or more than 4 tons of roots per acre in excess of the American yield. If we estimate that. by using higher grade seed, our yield would be increased by but onefourth of this difference or one ton to the acre, the yield in the United States would be increased by more than 300,000 tons, of which a 1,000 ton factory would receive 10,000 tons of roots. This would be the direct result of expending by such a factory, not to exceed $\$ 7,200$ additional for high-grade seed. This additional yield would be directly beneficial not only to the factories, but especially to the farmers, who in 1905 would have received more than $\$ 1,500,000$ additional for these roots, which would have been produced at practically no additional expense except for digging and hauling.

The United States Department of Agriculture has experiments under way to establish high-grade pedigree strains of seed for distribution to factories and seed growers, to determine the environmenta] influence of different sections on these strains, and to ascertain the comparative qualities of all varieties of sugar beet seed used in the United States, including both American and foreign sorts. This work has been established in connection with the New York Experi. ment Stations, at Geneva, N. Y.; the Michigan Experiment Station Agricultural College, Mich.; the Utah Experiment Station, at Logan Utah; and with individuals under Department supervision at Holland Mich., and Fairfield, Wash.

\section{THE ESTABLISHMENT OF PEDIQREE STRANNS OF BEED.}

When this work was inaugurated the best strains of European seec obtainable, as well as all obtainable American sorts, were secured anc planted side by side for comparison. The four sorts which showec the higher sugar content and purity and whose roots were most uni. form and of best size, shape, color, etc., were decided upon for use as foundation stocks from which to breed superior strains of seed. Roots 
from each of these stocks were individually analyzed and each one found to be of exceptional quality was carefully noted, numbered, and siloed for planting the coming spring as a mother. The seed from each of these mothers was harvested separately and in the following spring planted separately, and the products tested, the best being saved as foundation stocks for forming new families. These families were compared as to yield, sugar content, purity and correlated characteristics indicative of these qualities. Mother roots have since been selected from each of the families which have proven to be exceptional transmitters of their high qualities. During the past year we have raised some 1,400 pounds of seed from individually analyzed roots; testing from 18 to 24 per cent of sugar, depending upon the locality and the family. We also produced 20 acres of commercial seed which was grown from chemically analyzed grand-mothers testing $22 \mathrm{per}$ cent. Both of these lots of seed will be used for experimental work during the coming year. It is the purpose of the Department, as soon as a superior strain of seed has been established and fixed, to supply growers and factories with a sufficient quantity to use as stock seed.

TESTING THE COMPARATIVE MERITS OF SUGAR BEET SEED.

The work of testing the various varieties of seed has progressed satisfactorily and has shown that in almost every instance the American-grown seed has proven superior to the imported seed, in that it was of stronger germinating qualities, produced a better stand of seed, gave a larger yield, and in most cases the beets were higher in sugar content. Our experiments have further shown that much of the imported seed is of questionable quality.

The beet-sugar industry is now so well established in the United States that it is poor policy to longer depend upon imported seed for there is always the possibility that on account of the failure of the European crop, or for political reasons, our European supply may be cut off, in which case the beet-sugar industry of America would be completely paralyzed. Even if this possibility is regarded as remote it is nevertheless true that the American beet-sugar factories can never obtain the maximum profit until their beet seed is produced to meet the peculiar American conditions of soil and climate. The Department aims to assist sugar-beet seed growers and factories in producing their own seed by not only supplying them with high-grade seed with which to begin operations, but to increase the sugar content and yielding qualities as well. The Department's work in determining in which locality sugar beet seed can profitably be grown and the environmental conditions affecting the quality of such seed will also, we believe, be of great assistance in thoroughly establishing this industry in America. 